\title{
Neurodevelopmental outcome of preterm infants with bronchopulmonary dysplasia
}

\author{
Peter H Gray, Yvonne R Burns, Heather A Mohay, Michael J O’Callaghan, David I Tudehope
}

\begin{abstract}
The neurodevelopmental outcome of 78 infants with bronchopulmonary dysplasia (BPD) was compared with that of 78 control infants matched for birthweight. To determine the effect of the severity of BPD, 62 infants requiring oxygen at 36 weeks' postmenstrual age (sBPD) were compared with their matched controls. Infants were followed up to 2 years of age, corrected for prematurity, and were classified for neurological impairment, developmental delay, and neurodevelopmental disability. Seventy six (98\%) BPD infants and $71(91 \%)$ controls had follow up data available to two years. Neurological impairment, developmental delay, and neurodevelopmental disability occurred more frequently in infants with BPD than in controls but this was not significant. For infants with SBPD, the increased incidence of neurological impairment and definite developmental delay was not significant when compared with the controls, though neurodevelopmental disability occurred more frequently (odds ratio (OR) 3.6: 95\% confidence intervals (CI) 1.1-11.8). Predictors of disability in infants with sBPD included periventricular haemorrhage (OR 19.4: 95\% CI 4.3-86.6), ventric-

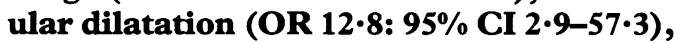
and sepsis (OR 5.0: 95\% CI 1.3-19.4). Adjusting for the presence of these factors, the association between BPD and disability was no longer apparent (OR 0.9: 95\% CI 0.2-3.6).
\end{abstract}

The findings suggest that BPD is not independently associated with adverse neurodevelopmental outcome.

(Arch Dis Child 1995; 73: F128-F134)

Keywords: preterm, bronchopulmonary dysplasia, neurodevelopmental outcome.

Advances in neonatal intensive care have resulted in a substantial increase in the survival of preterm infants, but the incidence of bronchopulmonary dysplasia (BPD) has increased concurrently. ${ }^{1}$ This is especially the case for infants of birthweight $<1000 \mathrm{~g}{ }^{2}$ though they frequently have a less severe form of the condition than that initially described by
Northway et al. ${ }^{3}$ Infants with BPD have been reported as having a high mortality both in hospital ${ }^{45}$ and after discharge, ${ }^{67}$ while follow up of survivors has shown an increased incidence of cardiopulmonary morbidity. ${ }^{8}$ Studies on neurodevelopmental outcome have produced varied results, with the rate of significant impairment ranging from $12-80 \%$. Interpretation of these reports is difficult, however, as no consistent definition of BPD has been used, ${ }^{7-11}$ sample sizes have been invariably small, ${ }^{12-15}$ and many have lacked con-

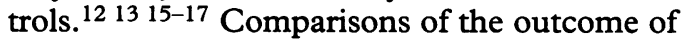
infants with and without BPD have been performed, though mostly the controls have had higher birthweights, ${ }^{211} 1819$ greater gestational age, ${ }^{7} 1920$ together with a lower incidence of intracranial haemorrhage. ${ }^{11} 19$

In recent years the radiographic changes of stage IV BPD, as described by Northway et al ${ }^{3}$ have been reported to occur less frequently in infants with $\mathrm{BPD},{ }^{21}$ though the subsequent neurodevelopment of these infants has not been well described. In the light of the changing pattern of chronic lung disease in preterm infants the present study was designed to follow up prospectively surviving preterm infants with BPD, together with controls matched for birthweight to determine and compare neurodevelopmental outcome.

\section{Methods}

The study population was obtained from admissions to the Mater Mothers' Hospital Neonatal intensive care unit, as described before ${ }^{22} 23$ and consisted of babies of 26-33 weeks' gestation born during 1989 and 1990 with the diagnosis of BPD at the time of discharge from hospital. The diagnosis of BPD required radiographical changes of chronic lung disease of prematurity, ${ }^{324}$ together with the clinical criteria of Bancalari et al ${ }^{25}$ : (1) intermittent positive pressure ventilation during the first week of life; (2) clinical signs of chronic respiratory distress persisting for more than 28 days; and (3) supplemental oxygen for more than 28 days to maintain adequate oxygenation.

Of the 539 infants of 26 to 33 weeks' gestation who were admitted to intensive care during the two year period, 50 (9\%) died, with 80 infants ( $16.4 \%$ of survivors) fulfilling the criteria for the diagnosis of BPD and being 
Table 1 Perinatal characteristics for bronchopulmonary dysplasia (BPD) and control infants

\begin{tabular}{lccl}
\hline & $\begin{array}{c}\text { BPD infants } \\
(n=78)\end{array}$ & $\begin{array}{c}\text { Control infants } \\
(n=78)\end{array}$ & Significance \\
\hline Antenatal corticosteroids & $36(46 \%)$ & $38(49 \%)$ & $\mathrm{NS}$ \\
Birthweight (g) mean (SD) & $1055(234)$ & $1077(215)$ & $\mathrm{NS}$ \\
$\quad($ range) & $(493-1770)$ & $(701-1650)$ & \\
Gestational age (weeks) mean (SD) & $28 \cdot 0(1 \cdot 58)$ & $28.63(1 \cdot 26)$ & $\mathrm{P}<0.05$ \\
$\quad$ (range) & $(26-33)$ & $(26-33)$ & $\mathrm{N})$ \\
Small for gestational age & $5(6.4 \%)$ & $9(11 \cdot 5 \%)$ & $\mathrm{NS}$ \\
Multiple pregnancy & $17(22 \%)$ & $5(13 \%)$ & $\mathrm{P}<0.05$ \\
Male:female sex & $44: 34$ & $43: 35$ & $\mathrm{NS}$ \\
Delivery & $33(42 \%)$ & $27(35 \%)$ & $\mathrm{NS}$ \\
$\quad$ Vaginal & $45(58 \%)$ & $51(65 \%)$ & \\
$\quad$ Caesarean section & $4.9(2 \cdot 2)$ & $5 \cdot 8(2 \cdot 5)$ & $\mathrm{P}<0.05$ \\
Apgar scores & $7.9(1 \cdot 7)$ & $8.5(1 \cdot 7)$ & $\mathrm{P}<0.05$ \\
$\quad$ 1 Minute - mean (SD) & & & \\
5 Minute - mean (SD) & &
\end{tabular}

NS: not significant.

discharged from hospital. Two infants with trisomy 21 were excluded from further assessment. The remainder were enrolled into the study.

The controls were the nearest appropriate infants of 26 to 33 weeks' gestation who were admitted to intensive care within a year of the study babies. As the incidence of BPD in infants of $<1000 \mathrm{~g}$ was $>50 \%$, a proportion of the controls were born in the year before or after the study years. No control infant required supplemental oxygen for more than 28 days and all were discharged home. These infants were matched with the study infants for broad based birthweight categories $(<1000 \mathrm{~g}$, $1000-1499 \mathrm{~g}, \geqslant 1500 \mathrm{~g}$ ). The selection of controls was made at, or shortly after, discharge from hospital with no knowledge of clinical events during the perinatal period, other than oxygen requirements.

In an attempt to determine the effect of the severity of BPD on neurodevelopmental outcome, infants who continued to have requirements for supplemental oxygen at 36 weeks postmenstrual age were considered to have more severe BPD (sBPD). It has been shown that a requirement for additional oxygen at 36 weeks corrected postnatal gestational age is a good predictor of abnormal pulmonary outcome. ${ }^{26}$ The 62 infants with sBPD were compared with their previously matched controls.

During the study period, infants were managed according to standard neonatal practices. All infants with respiratory distress were treated with appropriate ventilatory support. Artificial surfactant was not available for use during the period of study. The ventilated infants were given theophylline to facilitate

Table 2 Neonatal variables for bronchopulmonary dysplasia (BPD) and control infants

\begin{tabular}{llll}
\hline & $\begin{array}{c}B P D \text { infants } \\
(n=78)\end{array}$ & $\begin{array}{l}\text { Control infants } \\
(n=78)\end{array}$ & Significance \\
\hline Respiratory distress syndrome & $76(97 \%)$ & $42(54 \%)$ & $\mathrm{P}<0 \cdot 001$ \\
Transient tachypnoea of the newborn & $2(3 \%)$ & $22(28 \%)$ & $\mathrm{P}<0 \cdot 001$ \\
Mechanical ventilation (MV) & $78(100 \%)$ & $46(59 \%)$ & $\mathrm{P}<0 \cdot 001$ \\
Duration of MV (days) mean (SD) & $12 \cdot 2(10 \cdot 6)$ & $2 \cdot 8(2 \cdot 0)$ & $\mathrm{P}<0 \cdot 001$ \\
Pulmonary air leak & $12(15 \%)$ & $2(3 \%)$ & $\mathrm{P}<0 \cdot 05$ \\
Patent ductus arteriosus & $35(45 \%)$ & $8(10 \%)$ & $\mathrm{P}<0 \cdot 001$ \\
NEC & $4(5 \%)$ & $2(3 \%)$ & $\mathrm{NS}$ \\
Septicaemia & $16(21 \%)$ & $1(1 \%)$ & $\mathrm{P}<0 \cdot 001$ \\
Periventricular haemorrhage (PVH) & $17(22 \%)$ & $3(4 \%)$ & $\mathrm{P}<0.05$ \\
PVH - grade III-IV & $7(9 \%)$ & 0 & $\mathrm{P}<0.05$ \\
Ventricular dilatation & $12(15 \%)$ & $1(1 \%)$ & $\mathrm{P}<0 \cdot 05$ \\
Periventricular leucomalacia & $2(3 \%)$ & 0 & $\mathrm{NS}$ \\
Retinopathy of prematurity & $33(42 \%)$ & $14(18 \%)$ & $\mathrm{P}<0.01$ \\
\hline
\end{tabular}

NS: not significant; NEC: necrotising enterocolitis. weaning from the ventilator and those infants who required mechanical ventilation at 3 to 4 weeks of age were treated with dexamethasone. Oxygenation was monitored initially by arterial blood gas analysis and using a transcutaneous oxygen monitor. Later during the hospital stay pulse oximetry was used for assessment. When assisted ventilation was discontinued, infants were placed in head box oxygen. When the infants with BPD who had continuing supplemental oxygen requirements weighed $>1500$ $1800 \mathrm{~g}$, oxygen delivery was given by subnasal cannulae. Inspired oxygen was adjusted to ensure an oxygen saturation of 93-97\%. Infants who were feeding satisfactorily and gaining weight, but unable to maintain adequate oxygenation in room air, were discharged with home oxygen. They were only weaned off oxygen when overnight polygraphic sleep studies demonstrated normal oxygen saturations in room air at rest, during feeds, and while asleep.

Maternal characteristics, perinatal data, and details of the neonatal course of the infants were obtained from computer records and medical charts. Specific details pertaining to lung disease, pulmonary air leak, and respiratory therapy were noted. Additional neonatal complications recorded included patent ductus arteriosus, necrotising enterocolitis, and sepsis. Periventricular haemorrhage (PVH), ventricular dilatation, and cystic periventricular leucomalacia (PVL) were documented on the results of cranial ultrasonography which was performed as described before. ${ }^{27}$ Indirect ophthalmoscopy was first performed when infants were 4 weeks of age, or later if the clinical condition deemed ophthalmic examination inappropriate, to detect signs of retinopathy of prematurity (ROP). The most severe stage was recorded using the International Classification of Retinopathy of Prematurity. ${ }^{28}$ Infants with unresolved ROP at discharge had subsequent ophthalmological review.

\section{Follow up}

Infants after discharge were examined in the growth and development clinic at the Mater Children's Hospital at 4, 8, 12, and 24 months after the expected date of delivery. Growth parameters were recorded and a medical assessment, including a detailed neurological examination, was performed. Neurosensory motor developmental physiotherapy assessments were also conducted. Psychometric testing was performed at the age of 2 years using the Griffiths Infant Ability Scales ${ }^{29}$ (GQ mean 100, SD 12). For those infants who did not attend the clinic at the age of 2 years but who were assessed at a later stage, the McCarthy Scale of Children's Abilities ${ }^{30}$ was carried out (GCI mean 100, SD 16). Infants were classified according to the results of the most recent evaluation. Audiometric assessment consisted of conditioned orientated responses and impedance audiometry at the age of 12 months in addition to auditory brain stem response audiology which was carried out in hospital. 
Table 3 Perinatal characteristics for infants with more severe bronchopulmonary dysplasia (sBPD) and their controls

\begin{tabular}{|c|c|c|c|}
\hline & $\begin{array}{l}s B P D \text { infants } \\
(n=62)\end{array}$ & $\begin{array}{l}\text { Control infants } \\
(n=62)\end{array}$ & Significance \\
\hline Antenatal corticosteroids & \multirow{7}{*}{$\begin{array}{c}30(48 \%) \\
1071(236) \\
(680-1770) \\
28 \cdot 7(1 \cdot 6) \\
(26-33) \\
4(6 \%) \\
13(21 \%) \\
36: 26\end{array}$} & \multirow{6}{*}{$\begin{array}{c}31(50 \%) \\
1093(217) \\
(701-1616) \\
28 \cdot 6(1 \cdot 3) \\
(26-33) \\
7(11 \%) \\
5(8 \%) \\
34: 28\end{array}$} & \multirow{2}{*}{$\begin{array}{l}\text { NS } \\
\text { NS }\end{array}$} \\
\hline $\begin{array}{l}\text { Birthweight (g) mean (SD) } \\
\text { (range) }\end{array}$ & & & \\
\hline $\begin{array}{l}\text { Gestational age (weeks) mean (SD) } \\
\text { (range) }\end{array}$ & & & NS \\
\hline Small for gestational age & & & \multirow{4}{*}{$\begin{array}{l}\text { NS } \\
P<0.05 \\
\text { NS }\end{array}$} \\
\hline Multiple pregnancy & & & \\
\hline Male:female sex & & & \\
\hline Delivery & & & \\
\hline Vaginal & $25(40 \%)$ & $22(35 \%)$ & \multirow[t]{2}{*}{ NS } \\
\hline Caesarean section & $37(60 \%)$ & $30(65 \%)$ & \\
\hline \multicolumn{4}{|l|}{ Apgar scores } \\
\hline 1 Minute - mean (SD) & $4 \cdot 9(2 \cdot 3)$ & $5 \cdot 9(2 \cdot 6)$ & \multirow{2}{*}{$\begin{array}{l}\mathrm{P}<0.05 \\
\mathrm{NS}\end{array}$} \\
\hline 5 Minute - mean (SD) & $7 \cdot 9(1.8)$ & $8.5(1.8)$ & \\
\hline
\end{tabular}

NS: not significant.

Infants were classified for neurological impairment, developmental delay, and neurodevelopmental disability. Neurological impairment was defined as the presence of cerebral palsy or minor neurological dysfunction including hypotonia or ataxia. Mild cerebral palsy implied only slight interference with normal daily activities in children who were walking at the age of 2 years. Children with moderate cerebral palsy had more severe motor delay but were sitting unsupported at 2 years, while those with severe cerebral palsy were considered unlikely ever to walk. Developmental delay was classified according to the Diagnostic and Statistical Manual of Mental Disorders, ${ }^{31}$ diagnostic criteria using the Griffith or the McCarthy scores: borderline developmental delay, a GQ or GCI of between -1 and -2 SD; mild developmental delay, a GQ or GCI of between -2 and $-3 \mathrm{SD}$; moderate to severe developmental delay, a GQ or GCI of more than $-3 \mathrm{SD}$. Children with scores of more than $-2 \mathrm{SD}$ were considered to have definite developmental delay. Neurodevelopmental disabilities were classified as nil, mild, moderate, and severe based on a modification of the criteria of Ford $e a^{32}$ : nil, within the average range of developmental of age;

mild, a GQ or a GCI of between -1 and -2 $\mathrm{SD}$, or mild cerebral palsy or sensorineural deafness not requiring hearing aids, severe myopia, or severe strabismus; moderate, a GQ or a GCI of between -1 and -2 SD plus mild cerebral palsy or sensory impairment described as mild; severe, one or more of a GQ or a GCI of less

Table 4 Neonatal variables for infants with more severe bronchopulmonary dysplasia (sBPD) and their controls

\begin{tabular}{llll}
\hline & $\begin{array}{c}s B P D \text { infants } \\
(n=62)\end{array}$ & $\begin{array}{l}\text { Control infants } \\
(n=62)\end{array}$ & Significance \\
\hline Respiratory distress syndrome & $61(98 \%)$ & $11(18 \%)$ & $\mathrm{P}<0 \cdot 001$ \\
Transient tachypnoea of the newborn & $1(2 \%)$ & $18(29 \%)$ & $\mathrm{P}<0 \cdot 001$ \\
Mechanical ventilation (MV) & $62(100 \%)$ & $36(42 \%)$ & $\mathrm{P}<0 \cdot 001$ \\
Duration of MV (days) mean (SD) & $13(11 \cdot 2)$ & $1 \cdot 4(1 \cdot 6)$ & $\mathrm{P}<0 \cdot 001$ \\
Pulmonary air leak & $10(16 \%)$ & $1(2 \%)$ & $\mathrm{P}<0 \cdot 05$ \\
Patent ductus arteriosus & $27(44 \%)$ & $7(11 \cdot 3 \%)$ & $\mathrm{P}<0 \cdot 001$ \\
Necrotising enterocolitis & 0 & $1(2 \%)$ & $\mathrm{NS}$ \\
Septicaemia & $13(21 \%)$ & $1(2 \%)$ & $\mathrm{P}<0 \cdot 01$ \\
Periventricular haemorrhage (PVH) & $14(23 \%)$ & $3(5 \%)$ & $\mathrm{P}<0 \cdot 01$ \\
PVH - grade III-IV & $6(10 \%)$ & 0 & $\mathrm{NS}$ \\
Ventricular dilatation & $11(18 \%)$ & $1(2 \%)$ & $\mathrm{P}<0 \cdot 01$ \\
Periventricular leucomalacia & $1(2 \%)$ & 0 & $\mathrm{NS}$ \\
Retinopathy of prematurity & $26(41 \%)$ & $11(18 \%)$ & $\mathrm{P}<0 \cdot 01$ \\
\hline
\end{tabular}

NS: not significant. than $-2 \mathrm{SD}$, moderate, or severe cerebral palsy, bilateral blindness or deafness requiring hearing aids.

\section{STATISTICS}

Perinatal and neonatal characteristics of the BPD and control infants were compared using the $\chi^{2}$ test for categorical variables and Student's $t$ test for continuous variables. All $\mathrm{P}$ values were two tailed, and $P$ values of $<0.05$ were regarded as significant. The strength and precision of association between BPD and adverse outcomes was measured by the odds ratio (OR) and its $95 \%$ confidence interval (CI). Adjustment for confounding variables was by stratification and logistic regression, with risk of neurodevelopmental disability as the dependent variable. Presence of $\mathrm{PVH}$, ventricular dilatation, and sepsis were initially entered separately into the regression equation together with SBPD, then all three independent predictors were entered simultaneously. Analysis was performed using Statistix 4:0.

\section{Results}

No differences in the maternal age and education and marital and medical insurance status were found for the two groups of infants. Perinatal characteristics and neonatal variables for the BPD and control infants are shown in tables 1 and 2 . The mean birthweight and the number of small for gestational age infants were similar in both the study and control groups. The controls, however, had a gestational age of 28.6 weeks compared with 28 weeks in the BPD group $(\mathbf{P}<0.05)$. Infants born in association with multiple pregnancies were overrepresented in the BPD group and while no difference in the mode of delivery was present between the two groups, the BPD babies were more likely to be delivered in a depressed condition, as reflected by the lower Apgar scores. The study infants had more severe respiratory distress in the neonatal period, requiring mechanical ventilation more frequently and for longer duration than the controls. Neonatal complications related to the severity of respiratory distress and sepsis also occurred more frequently in the BPD infants. Six (7.7\%) of the infants with BPD had Northway stage IV radiographic changes, with the remainder having less severe changes consistent with those described by Edwards. ${ }^{24}$ The incidence of ROP was significantly higher in the BPD infants when compared with the controls. One BPD infant had stage III ROP, though this was not of a severity to warrant cryotherapy.

Similar findings were present when the 62 infants with sBPD and their controls were compared regarding their perinatal characteristics and neonatal variables (tables 3 and 4). In contrast to the BPD infants and controls, however, no significant difference in the gestational age between the sBPD infants and their controls was evident.

Follow up to at least 2 years was obtained for $77(98 \%)$ infants with BPD, while one was lost to follow up after the age of 8 months. One child 
Table 5 Neurological impairment in infants with bronchopulmonary dysplasia (BPD), severe $B P D(s B P D)$, and controls

\begin{tabular}{lllll}
\hline & $\begin{array}{l}\text { BPD infants } \\
(n=77)\end{array}$ & $\begin{array}{l}\text { Control infants } \\
(n=74)\end{array}$ & $\begin{array}{l}\text { sBPD infants } \\
(n=61)\end{array}$ & $\begin{array}{l}\text { Control infants } \\
(n=60)\end{array}$ \\
\hline None & $70(91 \%)$ & $72(97 \%)$ & $58(95 \%)$ & $58(97 \%)$ \\
Mild cerebral palsy & $1(1 \%)$ & $2(3 \%)$ & 0 & $2(3 \%)$ \\
Moderate cerebral palsy & $1(1 \%)$ & 0 & 0 & 0 \\
Severe cerebral palsy & $3(4 \%)$ & 0 & $2(3 \%)$ & 0 \\
Hypotonia/ataxic & $2(3 \%)$ & 0 & $1(2 \%)$ & 0 \\
\hline
\end{tabular}

had a Griffiths assessment performed by a local paediatrician with the remainder being assessed in the growth and development clinic. One infant was seen at 3 years (having failed to attend the clinic at 2 years) and had psychometric testing using the McCarthy scales. One BPD infant refused to cooperate for formal developmental testing and even though he was considered to be performing within the normal range no quantative measure could be obtained.

For the control infants, information concerning their outcome to at least 2 years was available for $71(91 \%)$ infants. Three were assessed at the age of 1 year (but subsequently became untraceable) and have been included in the analysis of neurological impairment, while the four infants who failed to attend the clinic have been excluded from all analyses of outcome. Local paediatricians performed psychometric assessment for two infants. Of those who attended the growth and development clinic, two had testing on the McCarthy Scale at the age of 4 years (they did not attend the clinic at 2 years), while four infants failed to cooperate for developmental testing. Despite no GQ score being obtained, two infants were found to be developing normally while the other two children were considered to be performing in the borderline developmental delay range following assessment by the developmental paediatrician.

\section{NEURODEVELOPMENTAL OUTCOME}

Table 5 shows the neurological impairment for the BPD infants and controls at the age of 1 year. Differences between the two groups were not significant (OR - 3.6; 95\% CI $0 \cdot 72-17 \cdot 9)$. The overall rate of cerebral palsy was $4 \cdot 6 \%$. Five $(6 \cdot 5 \%)$ infants with BPD had cerebral palsy (three spastic quadriplegia, one spastic diplegia, and one spastic hemiplegia), three of these infants with post haemorrhagic ventricular dilatation requiring a ventriculoperitoneal shunt. The one hypotonic infant also had hydrocephalus secondary to intraventricular haemorrhage and had a shunt inserted, while the ataxic infant had extreme intrauterine growth retardation. Two (3\%)

Table 6 Developmental status of infants with bronchopulmonary dysplasia (BPD), more severe $B P D$ ( $s B P D)$, and controls

\begin{tabular}{lclll}
\hline & $\begin{array}{l}\text { BPD infants } \\
(n=77)\end{array}$ & $\begin{array}{l}\text { Control infants } \\
(n=71)\end{array}$ & $\begin{array}{l}\text { sBPD infants } \\
(n=61)\end{array}$ & $\begin{array}{l}\text { Control infants } \\
(n=57)\end{array}$ \\
\hline $\begin{array}{l}\text { Normal } \\
\text { Borderline developmental delay }\end{array}$ & $63(82 \%)$ & $65(92 \%)$ & $49(80 \%)$ & $55(96 \%)$ \\
Mild developmental delay & $10(13 \%)$ & $5(7 \%)$ & $9(15 \%)$ & $1(2 \%)$ \\
$\begin{array}{l}\text { Moderate/severe developmental } \\
\text { delay }\end{array}$ & $1(1 \%)$ & $1(1 \%)$ & $1(2 \%)$ & $1(2 \%)$ \\
\hline
\end{tabular}

control infants had cerebral palsy, both with mild spastic diplegia.

Analysis of the results of the psychometric testing showed a mean score of $96 \cdot 3$ (SD 15.9) in the infants with BPD compared to 101.9 , (SD 10.2) in the controls $(P<0 \cdot 05)$. When the seven infants with grade III-IV $\mathrm{PVH}$ were excluded, the mean score in the BPD infants was 99.3 (SD 10.4) with no significance reached in comparison with the controls $(P=0 \cdot 14)$. Table 6 shows that while the incidence of developmental delay was higher in the BPD infants $(18 \%)$ when compared with the controls ( $8 \%$ ), this was not significant (OR $2 \cdot 4 ; 95 \%$ CI $0 \cdot 8-6 \cdot 7)$.

Neurodevelopmental disability was also seen more frequently in the BPD infants than in the controls (table 7 ), though again this was not significant (OR $2 \cdot 1 ; 95 \%$ CI $0 \cdot 8-5 \cdot 2$ ). Severe disability was present in five BPD infants on the basis of severe spastic quadriplegia $(n=3)$; a GQ $>-2$ SD below the mean in an infant who had hydrocephalus but no neurological impairment, and a further infant with sensorineural deafness requiring hearing aids.

Neurological impairment in the infants with SBPD was not statistically different from the controls (OR $1.5 ; 95 \%$ CI $0 \cdot 2-9 \cdot 3$ ) though notably, the controls with neurological impairment had only mild cerebral palsy (table 5). The mean score on psychometric evaluation of the infants with sBPD was 95.4 (SD 16.0), compared with $102 \cdot 1$ (SD 10.1) in their controls $(P<0.01)$. Once the infants with grade III-IV PVH had been excluded the mean psychometric score was 98.5 (SD 9.9), not significantly different from that of the controls $(P=0.09)$. On analysis of the developmental status, the infants with sBPD had a higher incidence of developmental delay than the controls (OR 6.7; 95\% CI 1.4-31.6) (table 6). Most of the developmental delay was in the borderline category in the infants with sBPD. No statistical difference in definite developmental delay was present in these infants when compared with the controls (OR 2.9; 95\% CI $0 \cdot 3-28 \cdot 7)$.

Table 7 indicates that neurodevelopmental disability was increased in $22 \%$ of the infants with sBPD compared with $7 \%$ of the controls (OR $3.59 ; 95 \%$ CI $1 \cdot 1-11 \cdot 8$ ). In the group of infants with sBPD, predictors of disability were PVH (OR 19.4; 95\% CI 4.3-86.6), ventricular dilatation (OR $12 \cdot 8 ; 95 \%$ CI $2 \cdot 9-57 \cdot 3$ ), and sepsis (OR 5.0; 95\% CI 1.3 - 19.4), while ROP did not predict disability (OR $0.8 ; 95 \%$ CI $0 \cdot 2-2 \cdot 8)$. Logistic regression analysis was performed with the risk of disability as the dependent variable. The findings confirmed those of the stratified analysis with the association between BPD and disability no longer being apparent when adjusted for the presence of $\mathrm{PVH}$, ventricular dilatation, and sepsis (OR $0 \cdot 9 ; 95 \%$ CI $0 \cdot 2-3 \cdot 6)$.

\section{Discussion}

Bronchopulmonary dysplasia occurred in $16.4 \%$ of survivors of 26 to 33 weeks' gestation discharged home during the years 1989 and 
Table 7 Neurodevelopmental disability in infants with bronchopulmonary dysplasia (BPD), more severe BPD (sBPD), and controls

\begin{tabular}{lclll}
\hline & $\begin{array}{l}\text { BPD infants } \\
(n=77)\end{array}$ & $\begin{array}{l}\text { Control infants } \\
(n=71)\end{array}$ & $\begin{array}{l}s B P D \text { infants } \\
(n=61)\end{array}$ & $\begin{array}{l}\text { Control infants } \\
(n=57)\end{array}$ \\
\hline Nil & $61(79 \%)$ & $63(89 \%)$ & $48(78 \%)$ & $54(93 \%)$ \\
Mild & $9(12 \%)$ & $7(10 \%)$ & $9(15 \%)$ & $3(5 \%)$ \\
Moderate & $2(3 \%)$ & 0 & 0 & 0 \\
Severe & $5(6 \%)$ & $1(1 \%)$ & $4(7 \%)$ & $1(2 \%)$ \\
\hline
\end{tabular}

1990, with sBPD (continuing supplemental oxygen requirement at 36 weeks postmenstrual age) in $12.7 \%$. This frequency was similar to that described elsewhere for a similar cohort of infants, ${ }^{33}$ though lower than that reported more recently for very low birthweight infants with chronic lung disease who required oxygen at 28 days. ${ }^{11} 1934$ The factors associated with the occurrence of BPD agree with those previously described, ${ }^{1} 1935$ though in our study data on intravenous lipid emulsion usage were not examined. As this was a birthweight matched study no difference in birthweight between the groups was seen. There was a statistical difference in gestational age between the BPD infants and the controls, but this was not considered to be of clinical significance. It was somewhat surprising that absence of corticosteroids was not associated with the development of BPD, as maternal administration of glucorticoids reduces the likelihood of respiratory distress syndrome, ${ }^{36}$ which is a risk factor for BPD.

Previous analysis of developmental outcome of infants with BPD has been inconclusive, largely because of the lack of consistency in the definition of BPD. Most early studies used the definition of oxygen dependence beyond 28 days together with the pulmonary radiographic changes described by Northway et al..$^{912-14}$ More recently, a definition based on that of Bancalari et al ${ }^{25}$ had been used. ${ }^{7} 171937 \mathrm{We}$ used the clinical criteria of Bancalari, together with the radiographic changes of Northway or Edwards, for our definition of BPD with only $7 \cdot 7 \%$ of our infants having Northway stage IV BPD. The requirement for supplemental oxygen at 36 weeks corrected postnatal gestational age has been shown to be a better predictor of abnormal pulmonary outcome in premature infants than requirement of oxygen at 28 days $^{26}$ It has been suggested, in light of the greater number of very preterm infants surviving, that this definition of BPD would be more appropriate. ${ }^{26} 38$ Infants requiring oxygen at 36 weeks gestation are likely to have a more severe form of BPD and hence this subgroup of infants was also evaluated in our study.

The incidence of cerebral palsy in previous reports of infants with BPD has ranged from $10 \%$ to as high as $67 \%$ in the small study of Goldson. ${ }^{14}$ When comparison between BPD and controls has been made, results have been somewhat conflicting. Sauve and Singhal ${ }^{7}$ and Davidson et al ${ }^{20}$ found no difference in the incidence of cerebral palsy between infants with or without BPD. Periventricular haemorrhage has been shown strongly to influence outcome and notably Sauve and Singhal ${ }^{7}$ found no difference in the incidence of PVH between the two groups while Davidson et al ${ }^{20}$ did not report on the results of cranial ultrasonography. The studies of Skidmore et al ${ }^{11}$ and Teberg et $a l^{19}$ both found an increased incidence of cerebral palsy in infants with BPD compared with controls, with the BPD infants having a significantly higher incidence of PVH. The incidence of cerebral palsy in our infants with BPD was somewhat lower than previously reported in BPD infants with similar birthweight and gestational age. We found a slightly greater incidence of cerebral palsy in both the BPD and SBPD infants when compared with the controls, but this did not reach significance. This may have occurred because even though the control infants had less PVH, the incidence of grade III-IV PVH in the BPD infants $(10 \%)$ was much lower than the $22-43 \%$ reported elsewhere in infants with chronic lung disease. ${ }^{11} 171937$ Cystic PVL has also been reported to be a significant predictor of cerebral palsy in preterm infants. ${ }^{39}$ In our study a low incidence of PVL was found, so no meaningful comment can be made concerning PVL and outcome in this group of infants with BPD.

Developmental delay has been reported in infants with BPD, with low MDI and PDI on the Bayley Scales. ${ }^{14} 40$ Sauve and Singhal ${ }^{7}$ found no evidence of increased incidence of developmental problems in infants with BPD when compared with controls. Skidmore et al ${ }^{11}$ reported a mean MDI of 84 in preterm infants requiring oxygen after 28 days compared with 94 infants on oxygen for less than three days while Teberg et al ${ }^{19}$ found that $40 \%$ of infants with BPD had abnormal development compared with $7 \%$ of infants without BPD. In both these studies, however, the BPD infants were less mature in gestational age, of lower birthweight, and had a higher incidence of PVH. While we found that the incidence of developmental delay was not increased in the BPD infants, they did have lower mean psychometric scores when compared with the controls. Notably, however, when the infants with major PVH were excluded, the infants with BPD did not differ significantly from controls. Our results contrast with those of Meisels et $a l,{ }^{10}$ who excluded infants with significant PVH and other neonatal morbidities known to be associated with adverse developmental consequences, and compared infants with RDS alone and those who developed BPD. Developmental outcomes of the infants with BPD in that study were significantly less optimal than the infants with RDS. Of the BPD infants, $35 \%$ displayed an MDI of $<85$ compared with $5 \%$ of infants with RDS. The reason for impaired development was not readily apparent, though possibly the development may have been affected by intermittent hypoxic episodes in hospital ${ }^{41}$ and after discharge home. ${ }^{42}$ In our study infants with BPD were closely monitored regarding their oxygenation status and the 20 infants who failed to demonstrate adequate oxygen saturations in air were discharged on the home oxygen programme. Supplemental oxygen was finally weaned from the infants at a mean age 
of 11 months. This may well have favourably influenced the outcome of infants with BPD, with $18 \%$ exhibiting developmental delay.

As in the report by Sauve and Singhal, ${ }^{7}$ we found no difference in the overall neurodevelopmental outcome of the BPD infants and controls. When the infants with more severe BPD (sBPD) were compared with their controls, the sBPD infants had a worse outcome, but this was no longer evident when confounding variables (PVH, ventricular dilatation, and sepsis) were taken into consideration. Bregman and Farrell ${ }^{43}$ compared preterm infants requiring oxygen therapy beyond 36 weeks of gestation with infants fulfilling the Northway criteria for BPD but not requiring oxygen by 36 weeks of gestation. The infants requiring oxygen at greater than 36 weeks of gestation had severe impairment more frequently than the comparison group, though by 2 years the Bayley Scores were comparable. Robertson et al ${ }^{44}$ examined a group of infants at the age of 8 years who had required supplemental oxygen beyond 36 weeks of gestation (infants with clinical intracranial haemorrhage were excluded). They found that the BPD infants had a similar incidence of disabled children (cerebral palsy, visual impairment, deafness or severe or profound retardation) to a preterm comparison group though the mean IQ scores were significantly less. The neurodevelopmental status at school age of low birthweight survivors born in the years 1975 to 1977 who developed BPD was also examined by Vohr et al. ${ }^{45}$ The BPD infants (having excluded those with cerebral palsy had greater motor coordination inefficiencies, increased perceptual motor integration problems, and increased arithmetic inefficiencies than both preterm and full term control infants. Both the study of Vohr et al ${ }^{45}$ and that by Robertson et al ${ }^{44}$ even though they were not representative of the small sick infants now surviving the newborn period, have highlighted the need for long term follow up. It may only be at school age that problems become apparent in many of these children that require greater need for academic support services.

In our study, we have shown that surviving infants with SBPD have a higher incidence of adverse neurodevelopmental outcome compared with preterm infants without this condition. When neonatal complications including $\mathrm{PVH}$, ventricular dilatation, and sepsis are taken into consideration, however, these infants do not seem to be at increased risk, and BPD per se is not a risk indicator of neurodevelopmental delay. On the basis of our data it is suggested that careful monitoring of oxygen saturation before discharge, together with enrolling infants in a home oxygen programme when appropriate, may have a beneficial effect on outcome. It is clear, however, that long term follow up of survivors of BPD to school age is important to obtain information on educational problems which may have important implications in future years.

This study was funded by the JP Kelly Mater Research Foundation and Queensland Sudden Infant Death Research Foundation.
1 Cooke RWI. Factors associated with chronic lung disease in preterm infants. Arch Dis Child 1991; 66: 776-9.

2 Northway WH. Bronchopulmonary dysplasia: then and now. Arch Dis Child 1990; 65: 1076-81.

3 Northway WH, Rosan RC, Porter DY. Pulmonary disease following respiration therapy of hyaline-membrane disease. $N$ Engl F Med 1967; 276: 357-68.

4 Abman SH, Burchell MF, Schaffer MS, Rosenberg AA. Late sudden unexpected deaths in hospitalised with bronchopulmonary dysplasia. Am ₹ Dis Child 1989; 143: 815-9.

5 Gray PH, Grice JF, Lee SM, Ritchie BH, Williams G. Prediction of outcome of preterm infants with severe Prediction of outcome preterm 1993; 29: 107-12.

6 Northway WH. Observations on bronchopulmonary dysplasia. $\mathcal{F}$ Pediatr 1979; 95: 815-8.

7 Sauve RS, Singhal N. Long-term morbidity of infants with bronchopulmonary dysplasia. Pediatrics 1985; 76: 725-33.

8 Bhutani VK, Abbasi S. Long-term pulmonary consequences in survivors with bronchopulmonary dysplasia. Clin Perinatol 1992; 19: 649-71.

9 Vohr BR, Bell EF, Oh W. Infants with bronchopulmonary dysplasia. Growth pattern and neurologic and developmental outcome. Am $\mathcal{F}$ Dis Child 1982; 136: 443-7.

10 Meisels SJ, Plunkett JW, Roloff DW, Pasick PL, Stiefel GS. Growth and development of preterm infants with respiratory distress syndrome and bronchopulmonary dysplasia. Pediatrics 1986; 776: 345-52.

11 Skidmore MD, Rivers A, Hask M. Increased risk of cerebral palsy among very low-birthweight infants with chronic lung disease. Dev Med Child Neurol 1990; 32: 325-32.

12 Marksted T, Fitzhardinge PM. Growth and development in children recovering from bronchopulmonary dysplasia. children recovering from br

13 Yu VYH, Orgill AA, Lim SB, Bajuk B, Astbur J. Growth and development of very low birthweight infants receiving from bronchopulmonary dysplasia. Arch Dis Child 1983; 58: 791-4.

14 Goldson E. Severe bronchopulmonary dysplasia in the very low birth weight infant: its relationship to developmental outcome. F Dev Behav Pediatr 1984; 5: 165-8.

15 Shankaran S, Szego E, Eizert D, Siegel P. Severe bronchopulmonary dysplasia. Predictors of survival and outcome. Chest 1984; 86: 607-10

16 Hudak BB, Allen MC, Hudak ML, Loughlin GM. Home oxygen therapy for chronic lung disease in extremely low-birth-weight infants. Am $\mathcal{F}$ Dis Child 1989; 143: 357-60.

17 Luchi JM, Bennett FC, Jackson JC. Predictors of neurodevelopmental outcome following bronchopulmonary developmental outcome following bronch

18 Mayes L, Perkett E, Stahlman MT. Severe bronchopulmonary dysplasia: a retrospective review. Acta Paediatr Scand 1983; 77: 225-9.

19 Teberg AJ, Pena I, Finello K, Aguilan T, Hodgman JE. Predition of neurodevelopmental outcome in infants with and without bronchopulmonary dysplasia. $\mathrm{Am} \mathcal{F} \mathrm{Med} S \mathrm{C} i$ 1991; 301: 369-74.

20 Davidson S, Schrayer A, Wielunsky E, Kirkler R, Lilos P, Reisner SH. Energy intake, growth, and development in ventilated very-low-birth-weight infants with and without bronchopulmonary dysplasia. Am $\mathcal{F}$ Dis Child 1990; 144: 553-9.

21 Hyde I, English RE, Williams JD. The changing pattern of chronic lung disease of prematurity. Arch Dis Child 1989; 64: 448-51.

22 Gray PH, Rogers Y. Are infants with bronchopulmonary dysplasia at risk for sudden infant death syndrome? Pediatrics 1994; 93: 774-7.

23 Chye JK, Gray PH. Rehospitalisation and growth of infants with bronchopulmonary dysplasia - a matched control study. F Paediatr Child Health 1995; 31: 105-11.

24 Edwards DK. Radiographic aspects of bronchopulmonary dysplasia. F Pediatr 1979; 95: 823-9.

25 Bancalari E, Abdenaur GE, Feller R, Gannon J. Bronchopulmonary dysplasia; clinical presentation. f Pediatr 1979; 95: 819-23.

26 Shennan AT, Dunn MS, Ohlsson A, Lennox K, Hoskins EM. Abnormal pulmonary outcomes in premature infants: prediction from oxygen requirement in the neonatal period. Pediatrics 1988; 82: 527-32.

27 Tudehope DI, Masel J, Mohay H, O'Callaghan M, et al. Neonatal cranial ultrasonography as predictor of 2 year Neonatal cranial ultrasonography as predictor of 2 year
outcome of very low birthweight infants. Aust Ped $\mathcal{F} 1989$; 25: $66-71$.

28 The Committee for the Classification of Retinopathy of Prematurity. An interventional classification retinopathy of prematurity. Arch Ophthalmol 1984; 102: 1130-4.

29 Griffiths R. The ability of young children. London: Child Development Research Centre, 1970.

30 McCarthy D. McCarthy's scales of children's abilities. New York: The Psychological Corporation, 1972.

31 Diagnostic and Statistics Manual of Mental Disorders. 3rd edn (revised). Washington, DC: American Psychiatric Association, 1987: 22-3.

32 Ford GW, Richards A, Kitchen WH, Lissenden JV, Keith CG, Ryan WH. Handicap and health problems in 2 year old children of birthweight 500-1500 g. Aust Ped f 1984; 21: $15-22$.

33 Hakulinen A, Heinonen $\mathrm{K}$, Jokela V, Kiekera $\mathrm{O}$. Occurrence, predictive factors and associated morbidity Occurrence, predictive factors and associated morbidity
of bronchopulmonary dysplasia in a preterm birth cohort. of bronchopulmonary dysplasia in

34 Hack M, Horbar JD, Malloy MH, Tyson JE, Wright E, Wright L. Very low birth weight outcomes of the National 
Institute of Child Health and Human Development Institute of Child Health and Human Deve

35 Corcoran JD, Patterson CC, Thomas PS, Halliday HL. Reduction in the risk of bronchopulmonary dysplasia 1980-1990: results of a multivariate logistic regression analysis. Eur F Pediatr 1993; 152: 677-81.

36 Crowley P, Chalmers I, Keirse MJNC. The effects of corticosteroid administration before preterm delivery: an overview of the evidence from controlled trials. $\mathrm{Br} \mathcal{F}$ Obstet Gynaecol 1990; 97: 11-25.

37 Lifschitz MH, Seilheimer DF, Wilson GS, Williamson WD, Thurber SA, Desmond MM. Neurodevelopmental status of low birthweight infants with bronchopulmonary dysplasia requiring prolonged oxygen supplementation. f Perinatol 1987; 7: 127-32.

38 Lipstein SV, Judak BB. Chronic lung disease. In: Jones $\mathrm{MD}$, Gleason CA, Lipstein SV, eds. Hospital care of the recovering NICU infant. Baltimore: Williams and Wilkins, 1991: 103-24.

39 De Vries LS, Dubouritz LM, Dubouritz V, Kaises A, Lary $S$, Silverman $M$, et al. Predictive value of cranial ultra$S$, Silverman M, et al. Predictive value of cranial ultra-
sound in the newborn baby: a reappraisal. Lancet 1985; ii: sound in th $137-40$.
40 Koops BL, Abram SH, Accurso FJ. Outpatient management and follow-up of bronchopulmonary dysplasia. Clin Perinatol 1984; 11: 101-22.

41 Garg M, Kurzner SI, Bautista DB, Keens TG. Clinically unsuspected hypoxia during sleep and feeding in infants with bronchopulmonary dysplasia. Pediatrics 1988; 81 635-42.

42 Singer L, Martin RJ, Hawkins SW, Benson-Szekely LJ, Yomashita TS, Carlo WA. Oxygen desaturation complicates feeding in infants with bronchopulmonary dysplasia. Pediatrics 1992; 90: 380-4.

43 Bregman J, Farrell E. Neurodevelopmental outcome in infants with bronchopulmonary dysplasia. Clin Perinato 1992; 19: 673-94.

44 Robertson CMT, Etches PC, Goldson E, Kyle JM. Eightyear school performance, neurodevelopmental and growth outcome of neonates with bronchopulmonary dysgrowth outcome of neonates with bronchopulmonary dys-

45 vohr BR, Coll CG, Lobato D, Yunis KA, O'Dea C, Oh W. Neurodevelopmental and medical status of lowbirthweight survivors of bronchopulmonary dysplasia at 10 to 12 years of age. Dev Med Child Neurol 1991; 33: 690-7. 